\title{
ROLE OF OBSTETRIC TRIAGE IN IMPROVING PATIENT HEALTH CARE AT CMH KHARIAN-A COMPARITIVE STUDY
}

\author{
Asma Ansari, Umbreen Akram, Hafsa Khalil*, Ayesha Imran**
}

Combined Military Hospital Kharian/National University of Medical Sciences (NUMS) Pakistan, *Armed Forces Institute of Cardiology/ National Institute of Heart Disease (AFIC/NIHD)/National University of Medical Sciences (NUMS) Rawalpindi Pakistan, ${ }^{* *}$ Combined Military Hospital Panu Aqil/National University of Medical Sciences (NUMS) Pakistan

\begin{abstract}
Objective: To evaluate the up gradation of obstetric patient care by using obstetrics-specific triage acuity tool. Study Design: Comparative prospective study.

Place and Duration of Study: This study was conducted at obstetrics unit of Combined Military Hospital (CMH) Kharian, from Jun to Dec 2018.

Methodology: Pregnant patients were triaged and prioritized according to maternal fetal triage index (MFTI) into five levels. Primary outcome was time to triage and management plan documentation. Patient and health care provider satisfaction was evaluated using Likert's scale before and after implementation of maternal fetal triage index. Data was collected and expressed in frequencies and percentage. Chi square test was applied for association between before and after triage intervention variables, and a $p$-value $\leq 0.05$ was considered significant.

Results: A total of 1000 pregnant patients referred to OPD were enrolled, 500 patients before and 500 after implemen-tation of triage. Patients were prioritized using maternal fetal triage system. Majority of the patients were in category five $244(48.8 \%)$ followed by category four $150(30 \%)$, category three $68(13.6 \%)$, category four $28(5.6 \%)$ and category one $10(2 \%)$ respectively. There was significant reduction in waiting time from $35.4 \pm 8.2$ minutes to $18.2 \pm 6.5 p<0.002$. Hospital complaints reduced significantly from $25(5 \%)$ in before group to $4(0.8 \%) p<0.001$ after application of obstetric triage.

Conclusion: Using a standardized triage system improved patient care and resulted in patient and provider satisfaction both. Patients waiting and disposal time were markedly reduced. There were significant reductions in hospital complaints, maternal and fetal morbidity and mortality.
\end{abstract}

Keywords: Maternal fetal triage index, Maternal mortality, Obstetric triage.

This is an Open Access article distributed under the terms of the Creative Commons Attribution License (http://creativecommons.org/licenses/by/4.0), which permits unrestricted use, distribution, and reproduction in any medium, provided the original work is properly cited.

\section{INTRODUCTION}

Achieving the Sustainable Development Goals (SDG) is anuphill task which the global health community is striving for. It is evident that reducing the world wide maternal mortality ratio to $<70 / 100,000$ live births will require holistic improvement in health care delivery systems ${ }^{1}$. In low and middle income countries, obstetric care is still focused on providing skilled home birth care and creating awareness and trust to seek antenatal care and institutional deliveries ${ }^{2,3}$. The lifetime risk of maternal death has fallen from 1 in 16 to 1 in 36 pregnancies in sub-Saharan Africa, but this statistic is still one of the biggest disparity between low and high income countries as

Correspondence: Dr Asma Ansari, House No. 38, Street No. 03, Askari 12, Rawalpindi Pakistan

Received: 03 Sep 2019; revised received: 07 Aug 2019; accepted: 18 Dec 2019 these women still face risk of death up to1000 times higher ${ }^{4}$. This disparity continues as women as patients also face many biases which might be cultural, institutional or at policy making level leading to poor funding and resource allocation to implement essential requirements in improving clinical practice.

A large number of patients are referred and checked in the Out Patient Departments and they need different levels of care attertiary care hospitals daily. They should receive care based on the intensity and severity of their condition, but unfortunately even after years and years of encountering obstacles or consequences of not having an organized system to classify the patients based on the urgency of their need for care, no such system of evaluation seems to be found in action country wide. Specifically, use of 
a standardized tool for this important purpose is practically nonexistent. Sadly this is not only the case for our country but something prevalent worldwide. For instance in a report evaluated and concluded by Association of Women's Hea1th, Obstetric and Neonatal Nurses (AWHONN) it was noted that in obstetric departments, the initial assessment of patients was traditionally done on a first-come, first-served basis and this is still in vogue at many places. One of the major problems with this approach although being in practice for so long is that it does not identify those women or their fetiwho need to be seen first according to their clinical condition rather than their time of reaching the facility thus causing the third delay in patient care the first two delays being patient associated and primary care provider delays 5 . AWOHNN recommends that triage should begin within 10 minutes of arrival to facility ${ }^{6}$. The purpose of triage is to decide that can a woman be sent home or should be admitted for inpatient care. Triaging also helps to decide how rapidly she needs management or further referral to higher Centre.

Evidently, this calls out for a tool to improve outcome through a standardized approach to obstetric triage. The Maternal Fetal Triage Index deserves attention from all obstetric professionals ${ }^{6}$. AWHONN recommended that triage of a pregnant woman is a brief, thorough and systematic method to quickly determine the urgency of disposal of woman and her fetus. It is the first obstetric acuity tool developed by a professional society for use across the United States in 2016, and after an efficiently conducted pilot study it is now being implemented in a huge number of obstetric patient care hospitals. According to recent national guidance in UK a delay of thirty minutes or more between reporting to hospital and triage can result in serious red flag obstetric events. This survey also demonstrated a wide variation in triage systems or no system at all resulting in some serious complications ${ }^{7}$. Non obstetric triage systems are being used worldwide but pregnancy and related conditions are special as there are certain conditions like preeclampsia peculiar to pregnancy and there are also fetal considerations. Some obstetric specific tools have been used sporadically like OTAS (Obstetric triage acuity scale) in Canada, MFTI and MEWS (Maternal early warning system) in USA, BSOTS (Birmingham symptom specific obstetric triage system) in $\mathrm{UK}^{8}$. American College of Obstetricians and Gynecologists recently also highlighted the requirement for developing standardized guidelines and strongly advocates the use of triage systems such as the one reported here to improve efficiency and quality of care ${ }^{9}$.

The study was conducted toevaluate outcome of the implementation of obstetric triage in our cultural relevance and observe the difference in outcome after its implementation and benefit in patient care.

\section{METHODOLOGY}

This study was conducted at department of obstetrics and gynecology CMH Kharian over a period of six months. A total of 1000 patients were enrolled by consecutive non probability sampling technique. Sample size was calculated with $95 \%$ confidence level, $5 \%$ margin of error by open epi sample size calculator by taking $37.2 \%$ prevalence of gynecology OPD patients ${ }^{10}$.

All pregnant patients presenting after twenty weeks gestation were included after informed consent and institutional review board permission (IERB CMH Khn-2932017). The study participants divided into two groups of 500 before and 500 after application of MFTI. All patients undergoing termination of pregnancy, and early pregnancy complications were excluded as majority of patients were unaware of their pregnancy status during early months of pregnancy. During the first phase traditional first come first serve method was used irrespective of the clinical condition. Then patients were triaged in the next phase of study. Staff was sensitized and trained to use MFTI by a series of workshops before starting the study project. The MFTI is a five-level tool arranged as an algorithm to triage patients presenting to an obstetric unit for any complaint. The main goal was to prioritize the urgency for health care 
provider evaluation which will lead to timely disposal. Each level assigns a priority according to the clinical condition hence a decision was lude chief complaint, vital signs and Fetal Heart Rate, fetal movements, contractions, bleeding, non-labor pain rating, coping with labor, mental

Table-I: Outcome before and after intervention.

\begin{tabular}{|c|c|c|c|}
\hline Variables & Before Intervention $(n=500)$ & After Intervention $(n=500)$ & $p$-value \\
\hline \multicolumn{4}{|l|}{ Place of Disposal } \\
\hline Intensive care & $35(7 \%)$ & $15(3 \%)$ & \multirow{5}{*}{$<0.001$} \\
\hline Labor room & $93(18.6 \%)$ & $93(18.6 \%)$ & \\
\hline OPD & $10(2 \%)$ & $10(2 \%)$ & \\
\hline OT & $42(8.4 \%)$ & $42(8.4 \%)$ & \\
\hline Ward & $320(64 \%)$ & $420(84 \%)$ & \\
\hline \multicolumn{4}{|l|}{ Referral Centre } \\
\hline Yes & $6(1.2 \%)$ & $7(1.4 \%)$ & \multirow{2}{*}{0.292} \\
\hline No & $494(98.8 \%)$ & $493(98.6 \%)$ & \\
\hline \multicolumn{4}{|l|}{ Patients Satisfaction } \\
\hline Strongly agree & $3(0.6 \%)$ & $147(29.4 \%)$ & \multirow{5}{*}{$<0.001$} \\
\hline Agree & $110(22 \%)$ & $249(49.8 \%)$ & \\
\hline Neutral & $325(65 \%)$ & $94(18.8 \%)$ & \\
\hline Disagree & $62(12.4 \%)$ & $6(1.2 \%)$ & \\
\hline Strongly disagree & - & $4(0.8 \%)$ & \\
\hline \multicolumn{4}{|l|}{ Provider Satisfaction } \\
\hline Strongly agree & - & $192(38.4 \%)$ & \multirow{5}{*}{$<0.001$} \\
\hline Agree & $115(23 \%)$ & $226(45.2 \%)$ & \\
\hline Neutral & $272(54.4 \%)$ & $79(15.8 \%)$ & \\
\hline Disagree & $113(22.6 \%)$ & $02(0.4 \%)$ & \\
\hline Strongly disagree & - & $01(0.2 \%)$ & \\
\hline \multicolumn{4}{|l|}{ Hospital Complaints } \\
\hline Yes & $25(5 \%)$ & $4(0.84 \%)$ & \multirow{2}{*}{$<0.001$} \\
\hline No & $475(95 \%)$ & $496(99.2 \%)$ & \\
\hline \multicolumn{4}{|l|}{ Maternal Morbidity } \\
\hline Yes & $72(14.4 \%)$ & $47(9.4 \%)$ & \multirow{2}{*}{0.009} \\
\hline No & $428(85.6 \%)$ & $453(90.6 \%)$ & \\
\hline \multicolumn{4}{|c|}{ Neonatal Intensive Care } \\
\hline Yes & $134(26.8 \%)$ & $97(19.4 \%)$ & \multirow{2}{*}{0.003} \\
\hline No & $366(73.2 \%)$ & $403(80.6 \%)$ & \\
\hline \multicolumn{4}{|c|}{ Intauterine Fetal Death } \\
\hline Yes & $11(2.2 \%)$ & $04(0.8 \%)$ & \multirow{2}{*}{0.005} \\
\hline No & $489(97.8 \%)$ & $496(99.2 \%)$ & \\
\hline \multicolumn{4}{|l|}{ Maternal Mortality } \\
\hline Yes & $4(0.8 \%)$ & $1(0.2 \%)$ & \multirow{2}{*}{0.001} \\
\hline No & $496(99.2 \%)$ & $499(99.8 \%)$ & \\
\hline \multicolumn{4}{|c|}{ Table-II: Time before and after intervention. } \\
\hline Group & Intervention & Mean \pm SD & $p$-value \\
\hline \multirow{2}{*}{ Waiting time } & Before $(n=500)$ & $35.49 \pm 8.268$ & \multirow{2}{*}{0.002} \\
\hline & After $(n=500)$ & $18.21 \pm 6.576$ & \\
\hline \multirow{2}{*}{ Disposal time } & Before $(n=500)$ & $57.75 \pm 18.089$ & \multirow{2}{*}{$<0.001$} \\
\hline & After $(n=500)$ & $27.66 \pm 11.467$ & \\
\hline
\end{tabular}

made which led to assigning an appropriate level of care. Each of the five levels has key questions with corresponding clinical conditions examples and parameters. Triage assessment elements inc- status, and pregnancy history, past obstetric history, past medical and surgical history, allergies and social history. The results obtained by applying the MFTI led to the staff issuing a specific 
colored card to the patient which indicated their level of urgency, assignment of care level and mobilization of resources. The goal was to reduce the time that elapses between presentation and provision of actual care according to prioritization. Level I/Stat red color signified immediate attention which could be life-saving for mother and baby, Level 2/Urgent orange colorwas severe pain not related to labor, high-risk condition which requires possible transfer. Level 3/ Prompt yellow colorwas pregnancy $\geq 34$ weeks in active labor or not coping with labor. Level $4 /$ Non-Urgent green color was pregnancy $\geq 37$ weeks with signs and symptoms of early labor or common pregnancy discomfort, Level 5/Scheduled blue color was requested services or scheduled procedures. Total number of patients presenting in each priority group were noted and frequency and percentage calculated.

Primary outcome was length of stay prior to triage and time to provider evaluation and management plan documentation. This time was measured both before and after implementation of MFTI system. Patient and health care provider satisfaction was also evaluated using Likert's scale and compared before and after implementation. Patients were triaged within hospital for higher level of care including intensive care, laborroom, operation theatre and ward. It also included patient in priority 4 and 5, who were seen and managed as outpatients. Also referral to higher tertiary care facility was observed.

Secondary outcome measured before and after implementation of MFTI were number of hospital complaints and liability and reportable incidents like maternal and fetal complications. Fetal complications including number of intrauterine fetaldeaths (IUFD) and Neonatal intensive care admissions were noted. Maternal morbidity and mortality was measured. Maternal morbidity parameters were preeclampsia/eclampsia, postpartum hemorrhage and preterm labor. Data was collected and analyzed using SPSS version 24 . Numeric variables were calculated as mean \pm SD and $t$-test was applied for significance. Categorical variables were expressed in percentage. Chi square test was applied to see the association of variables between before and after MFTI intervention, and a $p$-value of $\leq 0.05$ was considered significant for improvement in patient care. Fisher exact test was applied instead of chi square where necessary.

\section{RESULTS}

A sample of 1000 patients was taken from Obstetrics outpatient department of Combined Military Hospital Kharian. The study participants were divided into two groups; 500 before and 500 after application of MFTI. Five hundred Patients of MFTI group were further divided in sub categories (i.e. 1-5) on the basis of their condition. Majority of the patients were in category 5, 244 (48.8\%) followed by category 4, 150 (30\%),

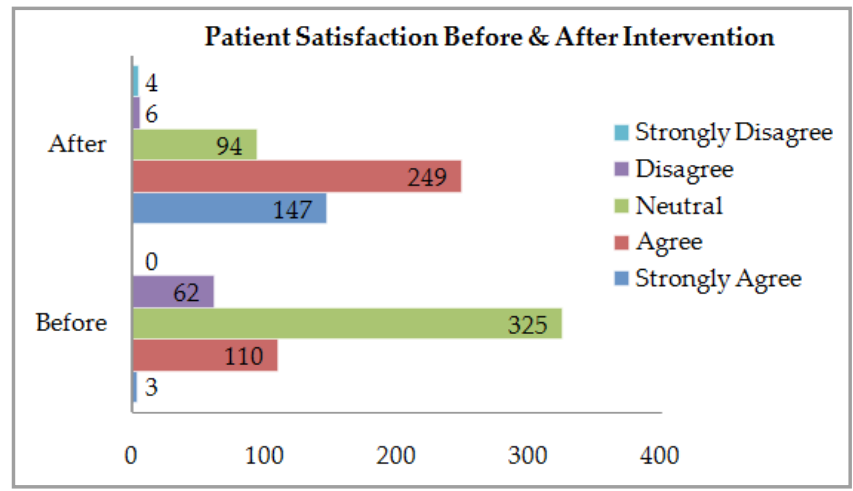

Figure-1: Provider and patient satisfaction.

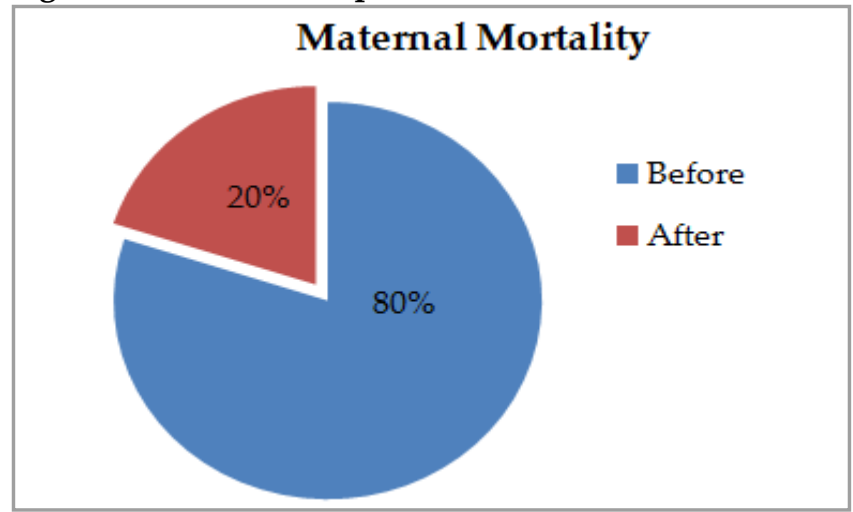

Figure-2: Maternal mortality before and after.

category 3, $68(13.6 \%)$, category 2, $28(5.6 \%)$ and category $1,10(2 \%)$ respectively. According to the need of patients they were referred to ICU, labor room, OPD, and ward before and after imple-mentation. Before intervention (table-I) large number of patients $320(64 \%)$ were admitted 
to ward and this number decreased without increase in complications thus reducing unnecessary burden on hospital wards. As after implementation of MFTI majority 296 (59\%) were managed in OPD due totriage. Results showed significant reduction in waiting time and disposal time from $35.4 \pm 8.2$ vs $18.2 \pm 6.5, p<0.002$ (tableII). Patient satisfaction improved significantly in after group with 147 (29\%) in strongly agree group vs $3(0.6 \%)$ before application of triage $p<0.001$. Similarly provider satisfaction also improved from $115(23 \%)$ before application of MFTI to $226(45.2 \%) \quad p<0.001$ after application (fig-1). Hospital complaints reduced significantly from $25(5 \%)$ to $4(0.8 \%) p<0.001$, after application of triage. Maternal morbidity in before and after group was $72(14.4 \%)$ vs $47(9.4 \%)$ with $p$-value $<0.009$ and neonatal morbidity was $134(26.4 \%)$ vs $97(19.4 \%)$ with $p$-value of $<0.003$. Two other important parameters which were measured in before and after group and showed significant improvement were IUDs $11(2.2 \%)$ in before group vs $4(0.8 \%) p$-value $<0.005$ in after group. Maternal mortality was $4(0.8 \%)$ maternal deaths in the group before application of triage to only 1 $(0.2 \%)$ death after application $p<0.001$ (fig-2).

\section{DISCUSSION}

Maternal fetal triage index is a high quality acuity tool for enhancement of patient health care and its validity has been established in studies ${ }^{11}$. Triage is a clinical assessment that sorts out patients for early diagnosis and treatment thus it is a risk management system employed in all busy emergency departments of hospital ${ }^{12}$. Considering the overcrowding and resource constraints in low and middle income countries extending it to the obstetric services would definitely improve services and satisfaction by prioritizing patients and reduce liability and complaints due to risk stratification. For an efficiently working triage system the backbone would be the health care staff not just the doctors. Midwives and resident doctors should be trained to triage patients and in this way they would be able to educate new staff and junior residents ${ }^{13}$. Major morbidity and mortality are essentially prevent- able and triaging the patients according to a standardized tool requires education, coordination, integration in hospital culture, practice alignment with other safety initiatives and administrative support ${ }^{14}$. In a study by Goodman et al. Waiting time for obstetric referrals was studied. Although women with significant risks like hypertensive disorders, obstetric hemorrhage and sepsis were seen earlier than baseline population, all groups failed to be evaluated with in standard 10 minutes when obstetric triage was not performed but median triage time was 55 minutes at night and 35 min during day. This was in comparison to our study in which triage time was $35 \mathrm{~min}$ before and $18 \mathrm{~min}$ after implementation of MFTI ${ }^{6}$. The results and conclusion of our study highlight the importance of usage of a triage system and its usefulness in low and middle income countries like in Ghana by Goodman et al11. Although it was the first time obstetric triage was used in our institution but we came close to the standard recommendation of ten minutes triagetime. A study by Kenyon et al, revealed thatafter application of obstetric triage women were assessed within $15 \mathrm{~min}$ of arrivaland waiting timewas reduced for assessment by qualified medical care provider from $30 \%$ to $54 \% p<0.0001$. This study used a four category scale BSOTS (Birmingham symptom specific obstetric triage system) to standardize care. Overall $90 \%$ involved agreed as compared to our study in which patients satisfaction was $80 \%$ and provider satisfaction $83 \% 15$. Forshaw et al, analyzed obstetric triage process at a large urban hospital in Uganda and employed a red 27\% (immediate), yellow 30\% (soon), green $41 \%$ (wait) and blue 2\% (routine) traffic Lights System for identifying high risk women. Although the triage tool was different, results were contrary as in our study $2 \%$ were in red category and majority were blue $48.8 \%$ and green $30 \%$. Only $14 \%$ of 700 patients were admitted over 10 days. The average wait time was 194 minutes which at night was longer. It was reduced to 38 minutes if triage personnel were present. The limitation was lack of dedicated triage personnel, a suitable examination area and equipment. Our 
median waiting time was reduced from 35 minutes to 18 minutes and 98 percent women were evaluated within 30 minutes of arrival. In a study by Forshaw et al, in 2016 evaluating the triage introduction intervention in a resource poor country hospital was done. The median waiting time from arrival to first assessment was reduced from $40 \mathrm{~min}$ to $15 \mathrm{~min} p<0.001$. The outcomes improved included decrease in patient waiting time and providing initial care and assessment. Implementation of triage system improved performance which resulted in minimum delays associated with the time ofadmission and disease acuity. Also the final care plan documentation increased from $51 \%$ to $96 \% 16$. This showed how the implementation of such a system in a low income hospital setting or one situated in a developing country can also equally benefit and progress by the use of triage system.

Apart from reduction in waiting time patient satisfaction also improved as shown by significant reduction in patient complaints from 5\% to $0.8 \%$ as shown in this study. Other outcome measures like number of IUFD reduced from 2.2 to $0.8 \%$, NICU admissions $26 \%$ to $19 \%$ and maternal morbidity from $14 \%$ to $9.4 \%$. These results emphasize the fact that application of standardized obstetric triage system improves mother and child safety, as also seen in other studies of emergency triage at a tertiary care hospital by Jawaid et al17,18. Although many other factors contribute to high maternal mortality and most important were the delay in reaching hospital as many patient were brought in critical condition, raising maternal mortality in hospital statistics, but even in critical patients triage leading to timely management saved many precious lives.

MFTI should be used in hospitals as well as primary care setups for timely disposal thus improving maternal and fetal outcome. Implementation of this system requires training and cooperation of all health care staff, because success and continuation of usage of an innovation is dependent on the user's ownership, practice and participation ${ }^{19}$. Triage studies in Pakistan have been done in fields of surgical emergencies while in obstetrics application of triage is novel idea in Pakistan. A surgical triage study carried in Pakistan showed inefficiency of surgical team as main factor of prolonged waiting time ${ }^{20}$. As in our study after training and implementing triage process all outcome measures improved. The major contribution of this studywas introducing idea of obstetric triage in busy obstetric units thus improving patient care and satisfaction. Limitation is that it is a single center study and more correlation is required between triage parameters and patient related factors.

\section{CONCLUSION}

Using a standardized triage system improved patient care. Implementing and using it was easy and resulted in patient and provider satisfaction both. Patients waiting and disposal time was markedly reduced. This way justice could be done in admission criteria. Provision of appropriate level of care could be expeditiously provided to patients. There were significant reductions in hospital complaints, maternal and fetal morbidity and mortality.

\section{CONFLICT OF INTEREST}

This study has no conflict of interest to be declared by any author.

\section{REFERENCES}

1. Sustainable Development Goals: Goal 3, Ensures healthy lives and promote wellbeing for all at all ages.UnitedNations: Department of Economic and social affairs, Sustainable Development: Knowledplatform. [Internet] Availableat at: https://sustainable development.un.org/sdg3 [Accessed jan 2019].

2. Althabe F, Bergel E, Cafferat ML, Gibbons L, Ciapponi A, Aleman A, et al. Strategies of improving the quality of health care in maternal and child health in low and middle-income countries: an overviews of systematic reviews. Paediatr Perinat Epedemol 2008; 229(Suppl-1): 42-60.

3. Campbell OM, Grahamw J. Lancet maternal survival series group. Strategies for reducing maternal mortality: getting on with what works. Lancet 2006; 368(9543): 1284-99.

4. Alkema L, Chou D, Hogan D, Zhang S, Mollar AB, Gemmill A, et al. A Global, regional and national levels and trends in maternal mortality between 1990 and 2015, with scenario based projections to 2030: a systematic analysis by the UN Maternal Mortality Estimation Inter Agency Group. Lancet 2016; 387(10017): 462-74.

5. Goodman DM, Srofenyoh EK, Olufolabi AJ, Kim SM, Owen MD. The third delay: understanding waiting time for obstetric referrals at a large regional hospital in Ghana. BMC Pregn Child 2017; 17(1): 216-23. 
6. AWHONN. Womens Health Perinatal Nursing Care Quality Measures Specifications 2013. [Internet] Available at http:// c.ymcdn.com/sites/www.awhonn.org/resource/resmgr/ Downloadables/perinatalqualitymeasures.pdf. [Accessed 3 feb 2018].

7. Safe midwifery staffing for maternity settings. National Institute for Health Care Excellence (NICE) Guideline NG4. Published February 2015. [Internet] https://www.nice.org.uk/guidance /ng4/chapter/1-Recommendations. [Accessed june 2018].

8. Veit-Rubin N, Brossard P, Gayet-Ageron A, Montandon CY, Simon J, Irion $\mathrm{O}$, et al. Validation of an emergency triage scale for obstetrics and gynaecology: a prospective study. Obstet J Gynaecol 2017; 124(1): 1867-73.

9. Hospital based triage of obstetric patients. Committee opinion no. 667. American college of Obstetricians and Gynecologists. Obstet Gynecol 2016; 128(1): e16-19.

10. Zafar S, Mahmood G. burden of gynaecological disease in a tertiary hospital: two years audit of outpatient department at PIMS. J Pak Med Assoc 2004; 54(1): 10-13.

11. Ruhl C, Scheich B, Onokpise B, Bingham D. Content validity testing of the maternal fetal triage index. J Obstet Gynecol Neonatal Nurs 2015; 44(6): 701-09.

12. Goodman DM, Srofenyoh EK, Ramaswamy R, Bryce F, Floyd L. Addressing the third delay: implementing a novel obstetric triage system in Ghana. BMJ Glob Health 2018; 3(1): e000623.
13. Angelini DJ, Stevens E, Mac Donald A, Weiner S, Wieczorek B. Obstetric triage: models and trends in resident education by midwives. J Mid Wom Health 2009; 54(4): 294-00.

14. Friedman MA. Implementing obstetric early warning system. Am J Perinatol Rep 2018; 8(2): e79-e84.

15. Kenyon S, Hewison A, Dann SA, Easterbrook J, HamiltonGiachritsis C. The design and implementa-tion of an obstetric triage system for unscheduled pregnancy related attendances: a mixed method evaluation. BMC Pregn Child 2017; 17(1): 309-12.

16. Forshaw J, Raybould S, Lewis E. Exploring the third delay: an audit evaluating obstetric triage at Mulago National Referral Hospital. BMC Pregn Child 2016; 16(1): 300-05.

17. Jones MK. Emergency Triage. Manchester Triage Group. $3^{\text {rd }}$ ed. London. England: BMJ Publishing Group; 1997. [Internet] Available at emj.bmj.com. [Accessed 8 feb 2019]. https:// onlinelibrary.wiley.com/doi/abs/10.1002/9780470757321.

18. Jawaid M, Amin MF, Khan RA, Iqbal SA. Waiting time for emergency surgeries in a Tertiary Care Public Hospital - A performance Audit. Pak J Med Sci 2005; 21(2): 133-37.

19. Paisley KS, Wallace R, DuRant PG. The development of an obstetric triage acuity tool. MCN Am J Matern Child Nurs 2011; 36(5): 290-96.

20. Fleiszer AR, Semenic SE, Ritchie JA, Richer MC, Denis JL. The sustainability of healthcare innovations: a concept analysis. J Adv Nurs 2015; 71(7): 1484-98. 